\title{
Prevalence and impact of acute renal impairment on COVID-19: a systematic review and meta-analysis
}

\author{
Xianghong Yang ${ }^{1 * \dagger}$, Yiyang Jin ${ }^{2 \dagger}$, Ranran $\mathrm{Li}^{3}$, Zhongheng Zhang ${ }^{4}$, Renhua Sun ${ }^{1}$ and Dechang Chen ${ }^{3,5^{*}}$
}

\begin{abstract}
Background: The aim of this study is to assess the prevalence of abnormal urine analysis and kidney dysfunction in COVID-19 patients and to determine the association of acute kidney injury (AKI) with the severity and prognosis of COVID-19 patients.

Methods: The electronic database of Embase and PubMed were searched for relevant studies. A meta-analysis of eligible studies that reported the prevalence of abnormal urine analysis and kidney dysfunction in COVID-19 was performed. The incidences of AKI were compared between severe versus non-severe patients and survivors versus non-survivors.

Results: A total of 24 studies involving 4963 confirmed COVID-19 patients were included. The proportions of patients with elevation of sCr and BUN levels were 9.6\% (95\% Cl 5.7-13.5\%) and 13.7\% (95\% Cl 5.5-21.9\%), respectively. Of all patients, $57.2 \%$ (95\% Cl 40.6-73.8\%) had proteinuria, 38.8\% (95\% Cl 26.3-51.3\%) had proteinuria + , and $10.6 \%$ (95\% Cl 7.9-13.3\%) had proteinuria ++ or +++. The overall incidence of AKI in all COVID-19 patients was $4.5 \%$ (95\% Cl 3.0-6.0\%), while the incidence of AKI was 1.3\% (95\% Cl 0.2-2.4\%), 2.8\% (95\% Cl 1.4-4.2\%), and $36.4 \%$ (95\% Cl 14.6-58.3\%) in mild or moderate cases, severe cases, and critical cases, respectively. Meanwhile, the incidence of AKI was $52.9 \%(95 \% \mathrm{Cl} 34.5-71.4 \%), 0.7 \%$ (95\% Cl - 0.3-1.8\%) in non-survivors and survivors, respectively. Continuous renal replacement therapy (CRRT) was required in 5.6\% (95\% Cl 2.6-8.6\%) severe patients, $0.1 \%(95 \% \mathrm{Cl}-0.1-0.2 \%)$ non-severe patients and $15.6 \%$ (95\% Cl 10.8-20.5\%) non-survivors and $0.4 \%(95 \% \mathrm{Cl}-0.2-$ $1.0 \%)$ survivors, respectively.

Conclusion: The incidence of abnormal urine analysis and kidney dysfunction in COVID-19 was high and AKI is closely associated with the severity and prognosis of COVID-19 patients. Therefore, it is important to increase awareness of kidney dysfunction in COVID-19 patients.
\end{abstract}

Keywords: 2019-nCoV, SARS-CoV-2, Renal impairment, Acute kidney injury, Continuous renal replacement therapy, Meta-analysis

\footnotetext{
* Correspondence: 18918520002@189.cn; jyy623@163.com

t'Xianghong Yang and Yiyang Jin contributed equally to this work.

'Department of Critical Care Medicine, Zhejiang Provincial People's Hospital,

Hangzhou Medical College, Hangzhou 310014, Zhejiang, People's Republic of

China

${ }^{3}$ Department of Critical Care Medicine, Ruijin Hospital, Shanghai Jiao Tong University School of Medicine, Shanghai 200025, People's Republic of China Full list of author information is available at the end of the article
}

(C) The Author(s). 2020 Open Access This article is licensed under a Creative Commons Attribution 4.0 International License, which permits use, sharing, adaptation, distribution and reproduction in any medium or format, as long as you give appropriate credit to the original author(s) and the source, provide a link to the Creative Commons licence, and indicate if changes were made. The images or other third party material in this article are included in the article's Creative Commons licence, unless indicated otherwise in a credit line to the material. If material is not included in the article's Creative Commons licence and your intended use is not permitted by statutory regulation or exceeds the permitted use, you will need to obtain permission directly from the copyright holder. To view a copy of this licence, visit http://creativecommons.org/licenses/by/4.0/. The Creative Commons Public Domain Dedication waiver (http://creativecommons.org/publicdomain/zero/1.0/) applies to the data made available in this article, unless otherwise stated in a credit line to the data. 


\section{Introduction}

Previous publications have shown that AKI developed in 5 to $15 \%$ cases and carried a high mortality rate (60 to 90\%) in SARS and MERS-CoV infections [1]. Recent studies have reported that acute renal impairment also occurs in COVID-19 patients. Cheng et al. have shown that among 710 consecutively hospitalized patients with COVID-19, 44\% had proteinuria and hematuria, and 26.7\% had hematuria on admission [2]. The incidence of elevated $\mathrm{sCr}$ and $\mathrm{BUN}$ was $15.5 \%$ and $14.1 \%$, respectively [3]. It has also been reported that the incidence rate of AKI in COVID-19 patients ranged from 0.5 to $29 \%$ dependent on the different severity of the illness. The AKI incidence was 0.1 to $2 \%$ for mild cases, $3-3.2 \%$ for severe cases, and up to $8.3-29 \%$ for critically ill patients that need to be admitted into the ICU [4-13].

In order to fully understand the prevalence and the clinical characteristics of kidney impairment in COVID19 patients, we have provided in this article a systematic review not only to evaluate the prevalence of acute renal impairment, but also to assess the risk of AKI in severely ill patients and non-survivors compared to non-severely ill patients and survivors, respectively. The findings in this article will help the clinicians to increase awareness of kidney impairment in COVID-19 patients.

\section{Methods}

Data source, search strategy, and exclusion criteria

We conducted a systematic search on PubMed and Embase from December 2019 to May 2020 and have used terms "COVID-19" and "novel coronavirus" in combination with terms including "clinical characteristics," "kidney injury," and "renal impairment" as keywords for literature search. The exclusion criteria included [1] studies that duplicate [2], studies on sample size smaller than 10 [3], studies that do not provide useful clinical characteristics or kidney impairment indicators [4], case reports, reviews or editorials [5], only children cases and family-based studies, and [6] studies written in Chinese (for the fear of data duplication). The literature search is shown step by step with a flow chart (Fig. 1). Two investigators worked independently to decide which studies should be included, and the disagreement was resolved by a third investigator.

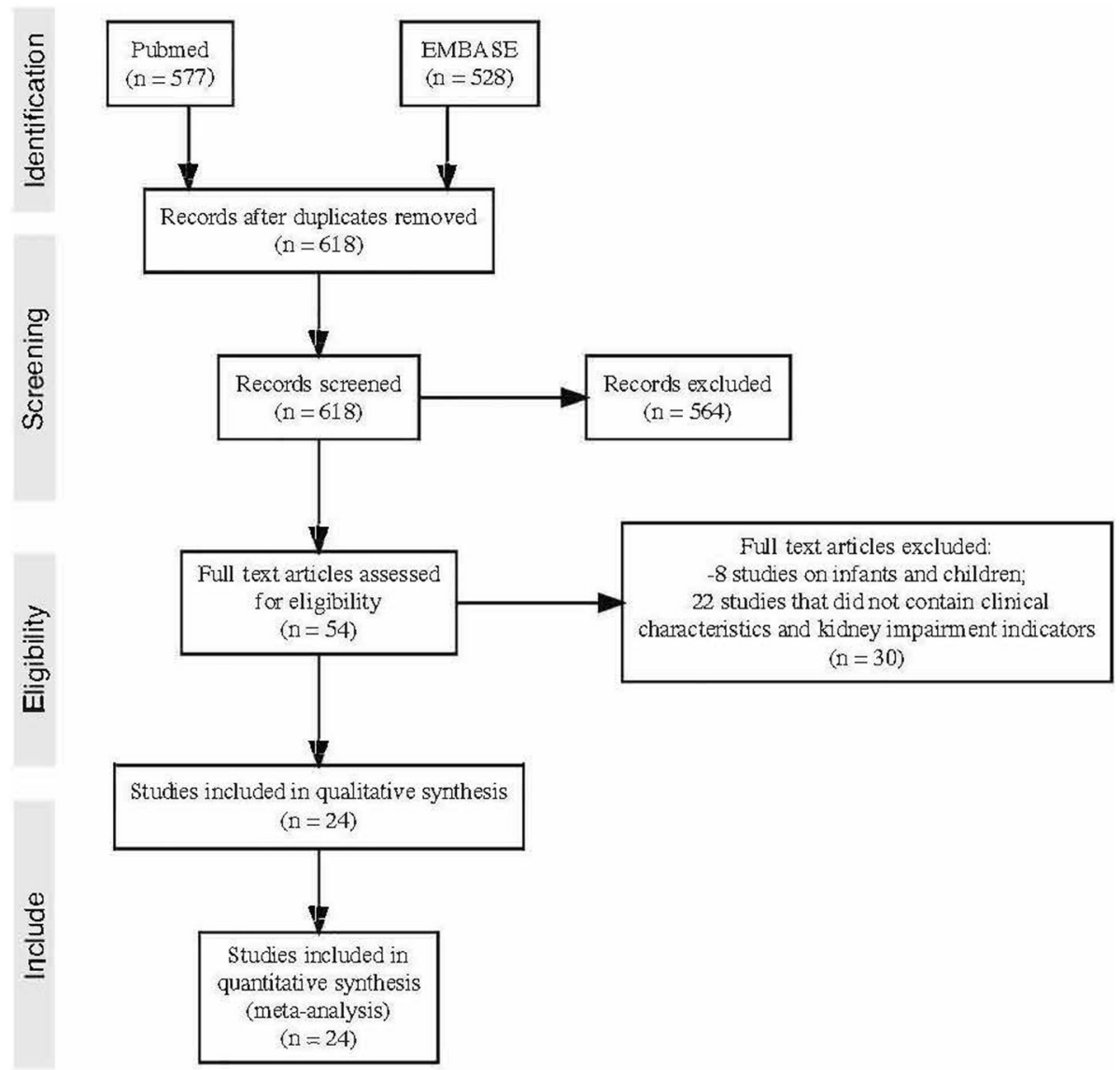

Fig. 1 Flow diagram of the selection process to identify the studies included in the meta-analysis 


\section{Data extraction}

After literature retrieval, we extracted the following parameters from 24 articles: $\mathrm{sCr}, \mathrm{BUN}$, elevation of $\mathrm{sCr}$, elevation of $\mathrm{BUN}$, incidence of $\mathrm{AKI}$, proteinuria, proteinuria + , proteinuria $++/+++$, the incidence of AKI in severely (including severe cases and critical cases) and non-severely (including mild and moderate cases) ill patients, the incidence of AKI in survivors and non-survivors, application of CRRT in severely ill and non-severely ill patients, and application of CRRT in survivors and non-survivors. The characteristics of these studies are shown in Table 1.

\section{Data analysis}

All analyses and plots were performed and made with the $\mathrm{R}$ version 3.6.3. For studies that did not provide mean and standard deviation but provided median ( $\mathrm{m}$ ) and upper (q3) and lower quartiles (q1) instead, the mean was estimated by $(\mathrm{q} 1+\mathrm{m}+\mathrm{q} 3) / 3$, and the standard deviation was estimated by $(\mathrm{q} 3-\mathrm{q} 1) / 1.35$ [14]. Forest plots were made to show the estimated mean and 95\% confidence interval of kidney indicators or prevalence and the corresponding 95\% CI of kidney impairment, respectively. The log risk ratios ( $\log \mathrm{RR}$ and $95 \% \mathrm{CI}$ ) were calculated to illustrate the relative risk of severe or non-survival patients to show AKI or to be supported with CRRT compared with non-severe or survival patients, respectively. The level of heterogeneity is defined based on the calculated $I^{2}$ : an $I^{2}$ smaller than $25 \%$ represents insignificant heterogeneity, an $I^{2}$ between $25 \%$ and 50\% represents low heterogeneity, an $I^{2}$ between $50 \%$ and $75 \%$ represents moderate heterogeneity, and an $I^{2}$ larger than $75 \%$ represents high heterogeneity [15]. A fixed effect model (inverse variance) was used to pool the data if $I^{2}<50 \%$, and a random effect model (DerSimonian-Laird) was used if $I^{2}>50 \%$ [16]. The threshold of statistical significance in this paper was set to be 0.05 .

\section{Results}

We initially identified 306 articles based on the search results, and 102 articles were recognized to be duplicates.

Table 1 Number, age, sex, and kidney impairment indicators, AKI incidence and CRRT application on COVID-19 patients of the 24 studies included

\begin{tabular}{|c|c|c|c|c|c|c|c|c|c|c|c|c|c|c|c|c|}
\hline \multirow[b]{2}{*}{$\begin{array}{l}\text { First } \\
\text { author }\end{array}$} & \multirow[b]{2}{*}{ Date(MM/DD) } & \multirow[b]{2}{*}{$\begin{array}{r}\text { Number } \\
\text { of case }\end{array}$} & \multirow[b]{2}{*}{ City } & \multirow[b]{2}{*}{ Age } & \multirow[b]{2}{*}{$\begin{array}{l}\text { Sex(male } \\
\%)\end{array}$} & \multirow[b]{2}{*}{$\begin{array}{l}\mathrm{sCr}(\mu \mathrm{mol} / \mathrm{L}) \\
(\mathbf{s d})\end{array}$} & \multirow[b]{2}{*}{$\begin{array}{l}\text { BUN(mmol/L) } \\
\text { (sd) }\end{array}$} & \multicolumn{8}{|c|}{$N(\%)$} & \multirow[b]{2}{*}{ Referance } \\
\hline & & & & & & & & $\begin{array}{l}\text { Eevated } \\
\text { sCr }\end{array}$ & $\begin{array}{l}\text { Elevated } \\
\text { BUN }\end{array}$ & Proteinuria & AKI & mortality & $\begin{array}{l}\text { ICU } \\
\text { admmision }\end{array}$ & CRRT & severe & \\
\hline Wang $\mathrm{D}$ & $2020-01-28$ & 138 & Whuan & $56(42-68)$ & 54.3 & $73(20)$ & $4.533(1.778)$ & I & , & 1 & $5(3.6)$ & $6(4.3)$ & $36(26.1)$ & $2(1.45)$ & I & 3 \\
\hline Chen & $2020-01-20$ & 99 & Wuhan & $\begin{array}{l}55.5(21- \\
82)\end{array}$ & 68.0 & $75 \cdot 6(25)$ & $5.9(2 \cdot 6)$ & $3(3.03)$ & $6(6.06)$ & 1 & $3(3)$ & 11(11) & $23(23)$ & $9(9)$ & 1 & 4 \\
\hline Yang $x$ & $2020-01-26$ & 52 & Wuhan & $\begin{array}{l}59.7(\mathrm{SD} \\
13 \cdot 3)\end{array}$ & 67.0 & $79(30.4)$ & 1 & 1 & I & 1 & $15(29)$ & $32(61.5)$ & $52(100)$ & $9(17)$ & 1 & s \\
\hline Huang $\mathrm{C}$ & 2020-01-02 & 41 & Wuhan & $49(41-58)$ & 73.0 & 1 & 1 & $4(10)$ & I & I & $3(7)$ & $6(15)$ & $13(31.7)$ & $3(7)$ & I & 6 \\
\hline Chen & $2020-02-06$ & 249 & Shanghai & $51(36-64)$ & 50.6 & 1 & 1 & I & I & 1 & 1 & $2(0.8)$ & $22(8.8)$ & 1 & 1 & 17 \\
\hline Huang $Y$ & $2020-01-29$ & 34 & Wuhan & $56(26-88)$ & 41.2 & t & 1 & $6(17.6)$ & 1 & 1 & 1 & 1 & $8(23.5)$ & 1 & 1 & 18 \\
\hline Liu & $2020-01-21$ & 12 & Shenzhen & $\begin{array}{l}53.9(10 . \\
72)\end{array}$ & 67.0 & $85.56(49.567)$ & $4.12(5.14)$ & $2(16.67)$ & $2(16.67)$ & I & $2(16.67)$ & 1 & I & 1 & I & 7 \\
\hline Li & $2020-02-07$ & 59 & $\begin{array}{l}\text { Wuhan } \\
\text { Chongqing } \\
\text { Huangshi }\end{array}$ & $52(28-83)$ & 57.7 & I & 1 & $11(19)$ & $16(27)$ & $\begin{array}{l}32 / 51 \text { (overall) } \\
24 / 51(+) \\
8 / 51(++/+++)\end{array}$ & 1 & 1 & t & $3(5.08)$ & $28(47.45)$ & 19 \\
\hline Arentz & 2020-03-05 & 21 & $\begin{array}{l}\text { Washington } \\
\text { state }\end{array}$ & $70(43-92)$ & 52.0 & $128.615(67.018)$ & I & 1 & I & 1 & $4(19.1)$ & $11(52.4)$ & $21(100)$ & $11(52.4)$ & I & 8 \\
\hline Yang $W$ & $2020-02-10$ & 149 & Wenzhou & 45.1 & 54.4 & $66.7(14.790)$ & $3.8(1.4)$ & $43(28.86)$ & I & I & $o(0)$ & $0(0)$ & $0(0)$ & I & I & 9 \\
\hline zhou & $2020-01-31$ & 191 & Whan & $56(46-67)$ & 62.0 & t & 1 & $8(4.3)$ & I & I & $28(15)$ & $54(28.27)$ & $50(26)$ & $10(5)$ & $119(62 \%)$ & 10 \\
\hline Qian & $2020-02-11$ & 91 & Zhejiang & $\begin{array}{l}50(36.5- \\
57)\end{array}$ & 40.66 & $66.917(14.259)$ & $3.91(0.881)$ & $3(3.3)$ & $1(1.1)$ & 1 & 1 & 1 & I & 1 & $9(10.23)$ & 21 \\
\hline Cheng & $2020-02-11$ & 710 & Wuhan & $63(51-71)$ & 52.7 & $83(84)$ & $6(5)$ & $110(15.5)$ & $100(14.1)$ & $\begin{array}{l}\text { 195/443(overall) } \\
150 / 443(+) \\
45 / 443(++++++)\end{array}$ & $22(3.2)$ & $89(12.5)$ & I & I & $252(35.5)$ & 2 \\
\hline Wan & $2020-02-08$ & 135 & Chongqing & $47(36-55)$ & 53.3 & $66.1(12.37)$ & 1 & 1 & I & 1 & $5(3.7)$ & $1(0.7)$ & 1 & 1 & $40(29.63)$ & 11 \\
\hline Guan & $2020-01-29$ & 1099 & China & $47(35-58)$ & 58.1 & 1 & 1 & I & I & 1 & $6(0.5)$ & $15(1.4)$ & I & $9(0.8)$ & $173(15.74)$ & 12 \\
\hline $\mathrm{xu}$ & $2020-01-26$ & 62 & Zhejiang & $41(32-52)$ & 56.0 & $72.333(17.037)$ & 1 & $3(5)$ & I & 1 & 1 & 0.0 & I & 1 & $2(3)$ & 20 \\
\hline Shi & $2020-02-10$ & 416 & Wuhan & $64(21-95)$ & 49.3 & $60.020(17.08)$ & ' & 1 & 1 & 1 & $8(1.9)$ & $57(13.7)$ & t & 1 & 1 & 13 \\
\hline $\mathrm{Hu}$ & $2020-02-20$ & 323 & Wuhan & $61(23-91)$ & 51.4 & t & , & $7(2.2)$ & $72(22.3)$ & I & $17(5.3)$ & 1 & $26(8.05)$ & I & $172(53.25)$ & 30 \\
\hline Pei & $2020-02-09$ & 333 & Wuhan & $56.3(13.4)$ & 54.7 & $70.333(520)$ & $4.3(3.2-5.7)$ & 1 & , & $219(65.8)$ & $35(10.5)$ & $29(8.7)$ & ' & I & $189(56.76)$ & 29 \\
\hline Wang L & $2020-02-13$ & 116 & Wuhan & $54(38-69)$ & $67(57.8)$ & $78.26(25.14)$ & $5.23(1.72)$ & $12(10.8)$ & , & I & 0.0 & 1 & 1 & 1 & $46(39.7)$ & 31 \\
\hline Agganwal & $2020-04-04$ & 42 & Des Moines & $\begin{array}{l}67 \text { (38- } \\
95)\end{array}$ & $12(75)$ & 1 & 1 & 1 & , & I & $11(69)$ & , & $8(50)$ & I & $16(100)$ & 26 \\
\hline Wang $D$ & $2020-02-10$ & 107 & Wuhan & $51(36-65)$ & $57(53.3)$ & $72.333(19.259)$ & ' & I & I & I & $14(13.11)$ & $19(17.76)$ & 1 & 1 & I & 27 \\
\hline Zhao & $2020-02-10$ & 91 & Jingzhou & 46.0 & $49(53.8)$ & I & 1 & $5(91 \%)$ & I & 1 & $5(5.5)$ & 1 & I & I & $30(33.3)$ & 28 \\
\hline Goyal & $2020-03-27$ & 393 & New York & $\begin{array}{l}62.2(48.6- \\
73.7)\end{array}$ & $238(60.6)$ & t & I & t & ' & 1 & 1 & $40(10.20$ & t & $18(4.8)$ & 1 & 32 \\
\hline
\end{tabular}


After removing the duplicates, the team members have carefully reviewed the titles, the abstracts, and the tables of the remaining 29 articles, and identified 24 articles [4-13, 17-28] that met our selection criteria and contained the data we need to investigate. These 24 articles were all published in 2020, and a total number of 4963 patients were included. The sample patient size of the groups ranged from 12 to 1099, and most of the studies recruited are based on patients in China, with three exceptions that focused on patients in the USA (Table 1).

Meta-analyses of these studies have shown that $9.6 \%$ (95\% CI $5.7-13.5 \%)$ and $13.7 \%$ (95\% CI $5.5-21.9 \%)$ of the patients showed an elevation in the $\mathrm{sCr}$ level and BUN level, respectively (Fig. 2). In addition, we have also conducted meta-analysis on the incidence of proteinuria of COVID-19 patients. Based on the three studies that contained data about proteinuria, 57.2\% (95\% CI 40.6$73.8 \%$ ) of all patients had proteinuria, 38.8\% (95\% CI $26.3-51.3 \%$ ) of all patients had proteinuria + , and $10.6 \%$ (95\% CI 7.9-13.3\%) of all patients had proteinuria ++ or +++ (Fig. 3). Heterogeneity was included in the abovementioned kidney impairment indicators except for the proportion of patients with proteinuria ++ or +++ , as the $I^{2}$ indexes were between 69.1 and $96.9 \%$, which were all above $50 \%$. The $I^{2}$ index of $8.40 \%(P$ value $=0.30)$ of the proteinuria ++ or +++ indicated that homogeneity was included.

The meta-analysis has shown that $4.5 \%$ (95\% CI 3.0$6.0 \%$ ) of COVID-19 patients had AKI (Fig. 4). The incidence of AKI was 1.3\% (95\% CI 0.2-2.4\%), 2.8\% (95\% CI $1.4-4.2 \%$ ), and $36.4 \%$ (95\% CI $14.6-58.3 \%$ ) in mild or moderate cases, severe cases, and critical cases, respectively (Fig. 5). The log risk ratio for severe patients to develop AKI compared with non-severe patients was 1.81 (95\% CI 1.21-2.41, $Z=5.88, P<0.01$, Fig. 4). The meta-analysis also showed that the incidence of AKI was $52.9 \%(95 \%$ CI $34.5-71.4 \%)$ vs $0.7 \%(95 \%$ CI $-0.3-1.8 \%)$ in non-survivors and survivors, respectively (Supplementary Figure 1). The log risk ratio to develop AKI for non-survivors compared to the survivors was 2.33 (95\% CI $0.88-3.78, Z=3.15, P<0.01$, Fig. 4).

Finally, CRRT was used on $5.6 \%$ (95\% CI $2.6-8.6 \%)$ severe patients, $0.1 \%$ (95\% CI $-0.1-0.2 \%)$ non-severe patients (Supplementary Figure 2) and 15.6\% (95\% CI $10.8-20.5 \%)$ non-survivors, $0.4 \%(95 \%$ CI $-0.2-1.0 \%)$ survivors (Supplementary Figure 3), showing the log risk ratio 3.34 (95\% CI 1.66-5.02, $Z=3.88, P<0.01)$ and 2.83 (95\% CI $1.57-4.10, \quad Z=4.38, \quad P<0.01$ ), respectively. (Fig. 6).

\section{Discussion}

Our meta-analysis showed that renal impairment in patients with COVID-19 is common. The manifestations of kidney damage are diverse, ranging from abnormal urine analysis, elevated $\mathrm{sCr}$ or BUN levels, to AKI and renal failure for which CRRT is required. Among these renal impairments, abnormal urine analysis is the most frequent. $57.2 \%$ patients have proteinuria, in which mild proteinuria $(+)$ as well as moderate or severe proteinuria (++ to +++ ) account for $38.8 \%$ and $10.6 \%$, respectively. Cheng's study has found that compared with patients without proteinuria, patients with proteinuria+ and ++ to +++ had a 1.5 -fold and fivefold increased risk of

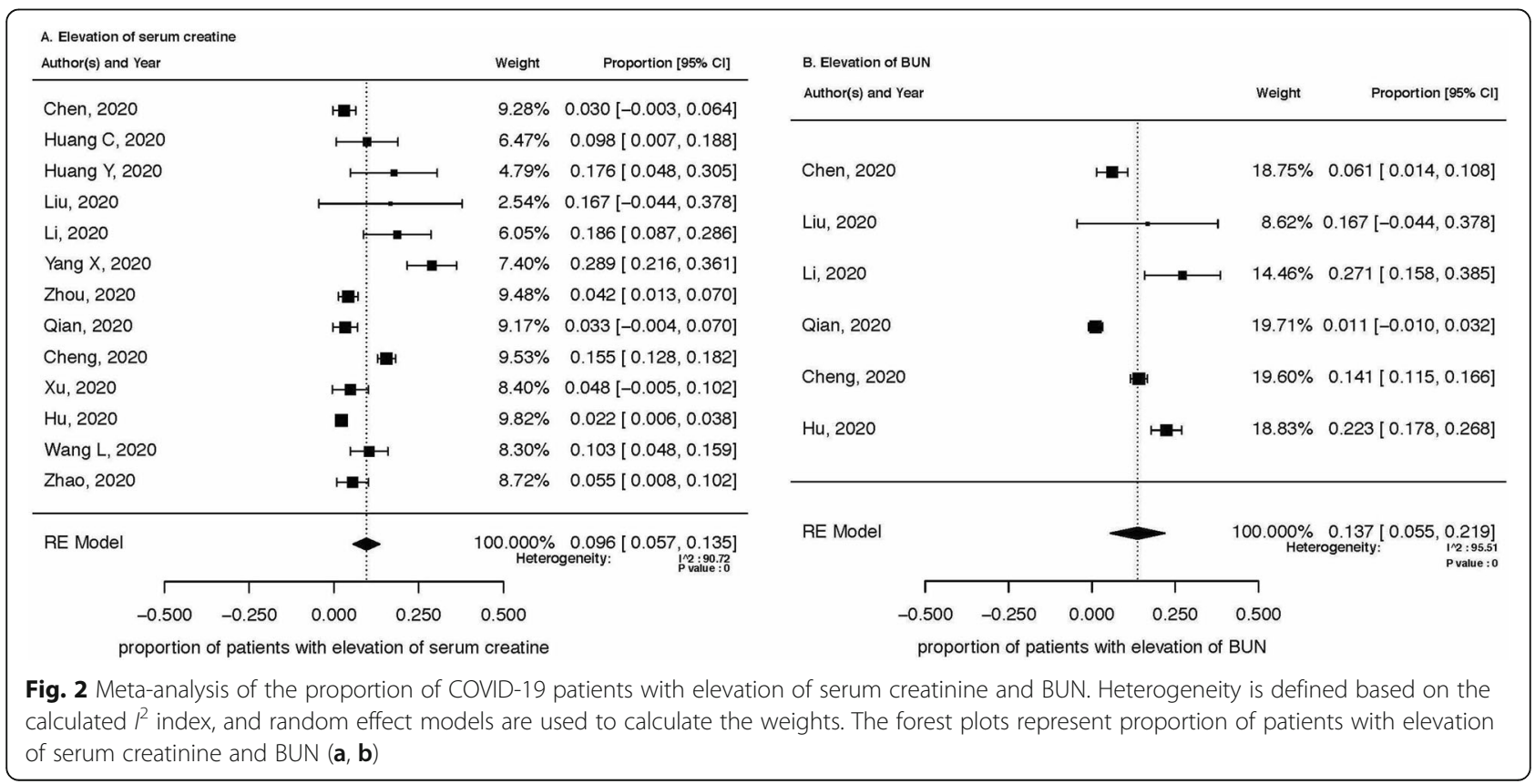




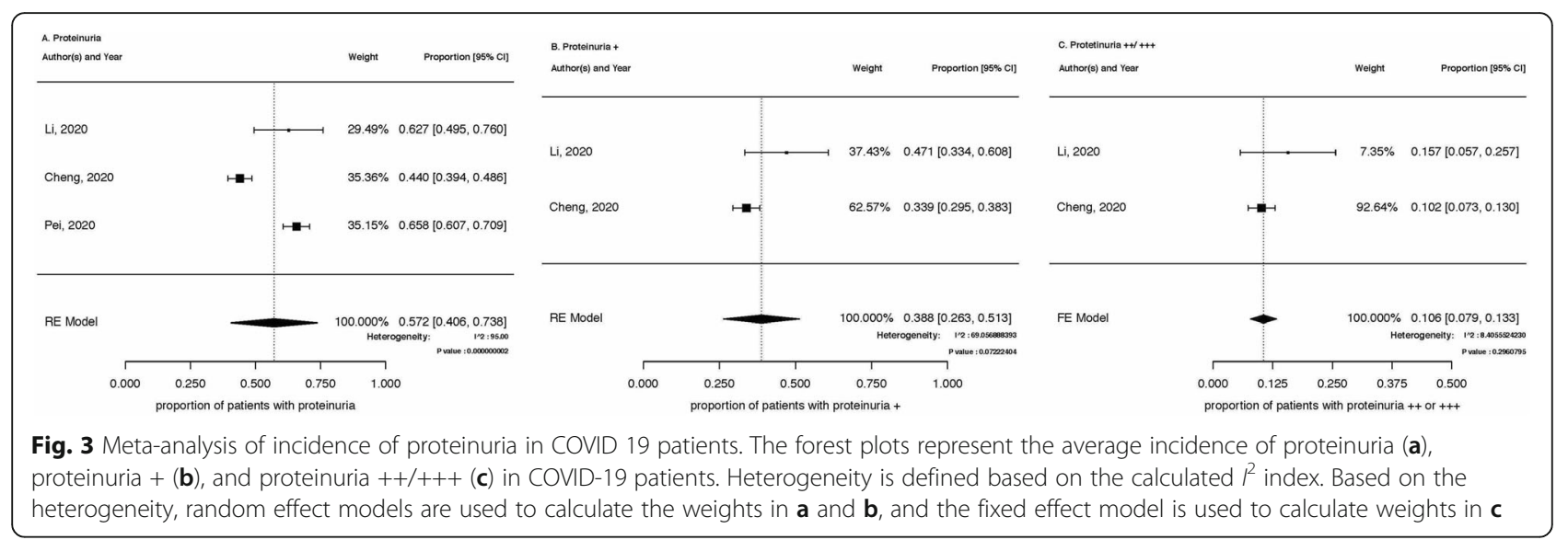

death, respectively, indicating that proteinuria is an independent risk factor for in-hospital death of COVID-19 patients [2], so more attention should be paid to urine analysis in clinical practice.

Another main kidney damage manifestation was elevated $\mathrm{sCr}$ and $\mathrm{BUN}$ levels with incidence rate of 9.6 and $13.7 \%$, respectively. Elevated $\mathrm{sCr}$ and BUN levels may be due to chronic kidney disease or AKI. Cheng's study showed that the baseline $\mathrm{sCr}$ was elevated in $15.5 \%$ COVID-19 patients on admission; patients with elevated baseline of $\mathrm{sCr}$ were more likely to develop AKI and more severe AKI. Meanwhile, elevated baseline $\mathrm{sCr}$ and BUN levels was an independent risk factor for hospital mortality [2]. Therefore, we should increase more awareness to COVID-19 patients who had elevated baseline $\mathrm{sCr}$.

Our meta-analysis showed that the averaged incidence of AKI was 4.5\%, ranging from 1.3 to $36.4 \%$ dependent on the different severity of the illness. The exact pathogenesis of COVID-19-associated AKI is unclear. Based on the results of our meta-analysis in combination with our frontline experience, we consider that the etiology of renal impairment is likely to be diverse and multifactorial. Besides the direct attack by the SARS-CoV-2, hypoxia and hypercoagulability also contribute to kidney damage.

It has been reported that in the kidney, angiotensinconverting enzyme2 (ACE2) is highly expressed in the brush border of proximal tubular cells but not in glomerular endothelial and mesangial cells [29], which could explain the fact that the main feature of kidney injury is the damage of renal tubules. Zhong's team in Guangzhou has also successfully isolated SARS-CoV-2 from the urine sample of an infected patient [30]. It also has been found in the kidney biopsy that SARS-CoV-2 antigens accumulated in kidney tubules in situ [31, 32]. These evidences supported the notion that SARS-CoV-2 can directly attack human kidney. In addition, COVID-19 patients exhibit obvious hypoxia symptoms and renal tubules are more susceptible to ischemia and hypoxia compared to glomeruli. Moreover, COVID-19 patients mainly showed hypercoagulant states with elevated levels of D-dimer, leading to the slow blood flow velocity in the capillaries around the renal tubules and increased risk of microthrombus formation as confirmed by autopsy results [33].

In contrast to the previous study showing that median time for the occurrence of AKI from symptom onset
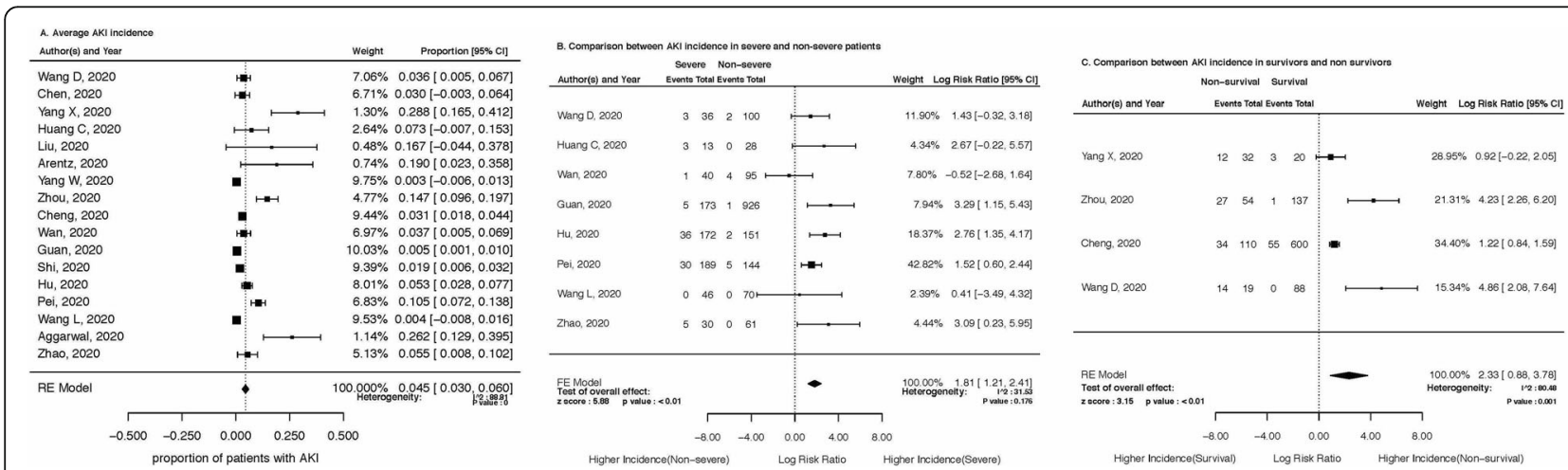

Fig. 4 a Forest plot of average AKI incidence in all COVID-19 patients. b Forest plots of AKI log risk ratio between severe and non-severe patients. c Forest plots of AKI log risk ratio between survival and non-survival cases. Heterogeneity is defined based on the calculated $P$ index, and random effect models are used to calculate the weights 

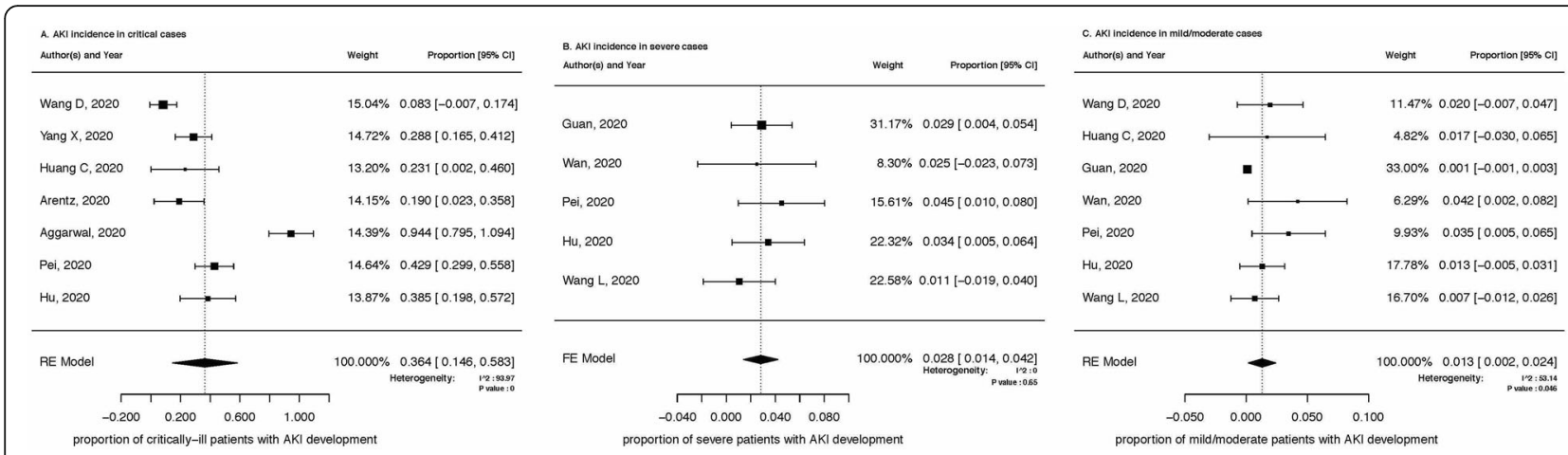

Fig. 5 a Forest plot of average AKI incidence in critical COVID-19 cases. b Forest plot of average AKI incidence in severe COVID-19 cases. c Forest plot of average AKI incidence in mild/moderate COVID-19 cases. Heterogeneity is defined based on the $P$ index calculated. A random effect model is used to pool the average AKI incidence in critical patients, and fixed effect models are used to pool the data of AKI incidence in severe and mild/moderate cases

were 20 and 16 days in SARS and MERS patients, respectively [1], Cheng et al. have found that AKI developed 6 days after admission in most COVID-19 patients while only 2 days after admission in patients with elevated baseline of $\mathrm{sCr}$ [2]. Our meta-analysis also revealed that the incidence of AKI was more than fivefold higher in severe cases and non-survivors than that in non-severe cases and survivors. Since severe COVID-19 is commonly complicated with ARDS which has high demand for fluid management, optimizing fluid volume and maintaining hemodynamic stability are crucial to prevent the occurrence or progression of AKI. In addition, appropriate anticoagulant therapy might help to reduce the microthrombus formation and to alleviate renal injury.

Our meta-analysis also showed $15.6 \%$ non-survivors received CRRT, while $0.4 \%$ survivors needed CRRT, which indicated that COVID-19 patients complicated with AKI have a poor prognosis once CRRT is applied. As existing studies have not provided detailed information about survivors and non-survivors experiencing CRRT, further research is needed to determine whether early renal replacement therapy could improve the prognosis of COVID-19 patients complicated with AKI.

\section{Study limitations}

The number of studies included was limited in terms of sample size, data availability, and methodologic quality, as most of the patients were from China. It will be better to include more studies with a broad geographic scope, to get a more comprehensive understanding of acute renal impairment in COVID-19. In addition, more detailed patient information, particularly regarding the

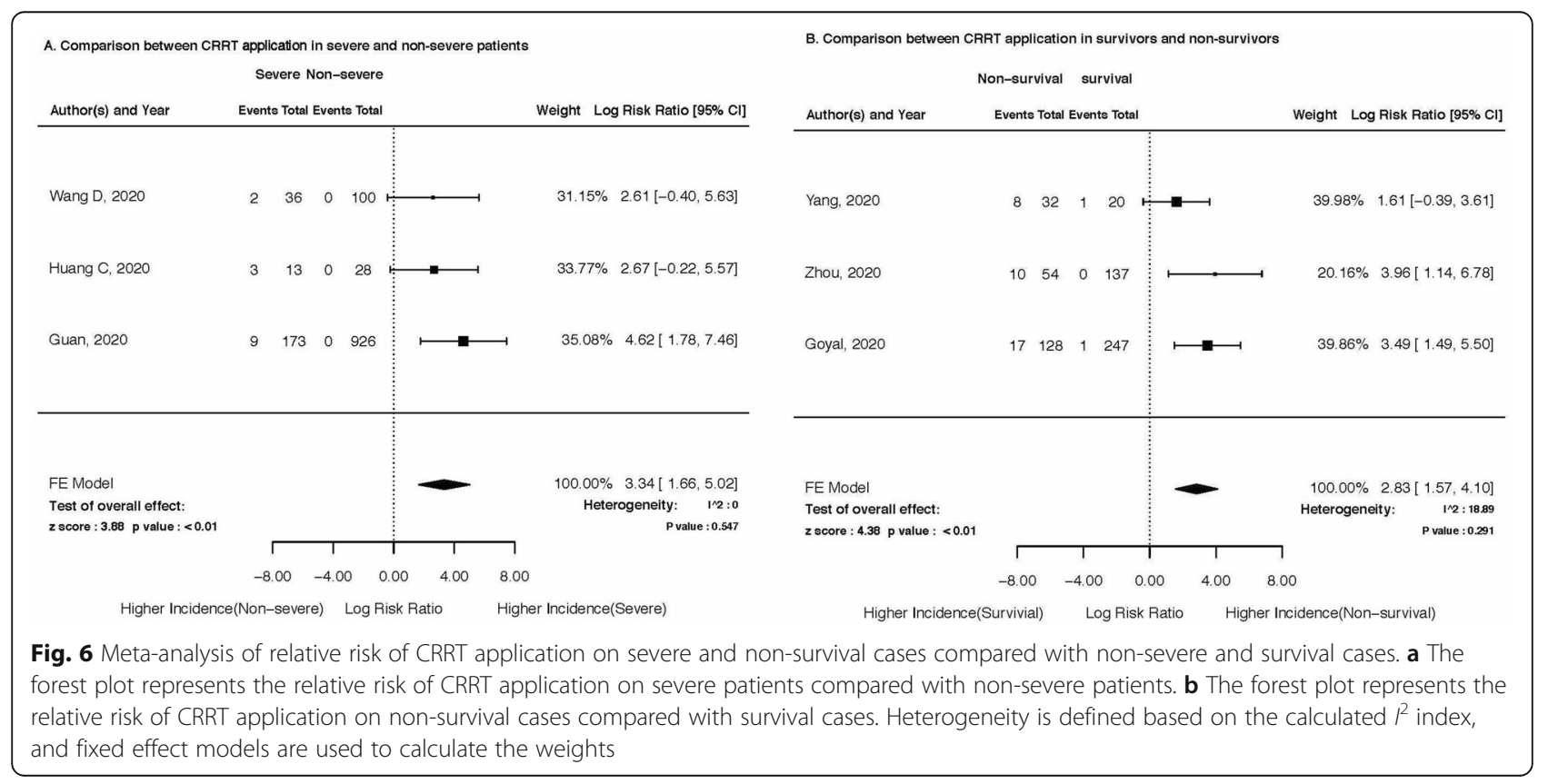


risk of AKI and the relationship of comorbidities with AKI, was not available in most studies at the time of analyses. Another limitation of this study is that some articles have provided median and interquartile ranges but not mean and standard deviation of the $\mathrm{sCr}$ and BUN values. The mean and standard deviation for those data has been estimated in this study based on the median and the interquartile range, which might lead to inaccuracy to some extent.

\section{Conclusion}

Although ARDS was the main feature of COVID-19, our meta-analysis identified the high prevalence of abnormal urine analysis and kidney dysfunction in COVID-19 patients. The overall incidence of AKI in COVID-19 patients was $3.7 \%$, and the degree of AKI is closely associated with the severity and prognosis of COVID-19 patients.

We consider renal tubule as the main part of injury in COVID-19 patients and the etiology of renal impairment in COVID-19 patients is likely to be diverse and multifactorial. Apart from direct attack by the SARS-CoV-2, hypoxia and hypercoagulability may also contribute to the occurrence of renal injury.

Our findings indicate that it is important to increase awareness of kidney impairment in COVID-19 patients. Screening of the urine analysis, more frequent measurement of sCr, optimization of fluid volume, and appropriate anticoagulant therapy during the management of COVID-19 are essential.

\section{Supplementary information}

Supplementary information accompanies this paper at https://doi.org/10. 1186/s13054-020-03065-4.

Additional file 1 : Supplementary Figure 1. Meta-analysis of the mean value of serum creatinine and BUN in COVID-19 patients. Heterogeneity is defined based on the calculated $\mathrm{I}^{2}$ index, and random effect models are used to calculate the weights. The forest plots represent mean values of serum creatinine $(A, B)$ and $B U N(C, D)$.

Additional file $\mathbf{2}$ : Supplementary Figure 2. A: Forest plot of average AKI incidence in non-survivors. B: Forest plot of average AKI incidence in survivors. Heterogeneity is defined based on the $\mathrm{I} 2$ index calculated. A fixed effect model is used to pool the average AKI incidence in non-survivors, and a random effect model is used to pool the data of AKI incidence in survivors.

Additional file $\mathbf{3}$ : Supplementary Figure 3. A: Forest plot of average proportion of severe patients who required CRRT. B: Forest plot of average proportion of mild patients who required CRRT. Heterogeneity is defined based on the 12 index calculated. Fixed effect models are used to pool data of both groups.

Additional file 4 : Supplementary Figure 4. A: Forest plot of average proportion of non-survivors who required CRRT. B: Forest plot of average proportion of survivors who required CRRT. Heterogeneity is defined based on the 12 index calculated. Fixed effect models are used to pool data of both groups.

\section{Acknowledgements}

The authors would like to express their appreciation for all of the health care workers and other hospital staff as well as the local authorities for their efforts to combat the outbreak of COVID-19.

\section{Authors' contributions}

All the authors have participated in literature retrieval and viewpoint discussion in this article. Xianghong Yang and Yiyang Jin contributed in writing this article. Yiyang Jin did the statics. Dechang Chen revised this article. All authors read and approved the final manuscript.

\section{Funding}

This study was supported by the Key Research and Development Plan of Zhejiang province (2019C03024), Zhejiang Medical and Health Technology Platform Project (2017ZD002).

Availability of data and materials

Not applicable

Ethics approval and consent to participate

The study does not require ethical approval because the meta-analysis is based on published research and the original data are anonymous.

Consent for publication

Not applicable

\section{Competing interests}

The authors declare that they have no competing interests.

\section{Author details}

${ }^{1}$ Department of Critical Care Medicine, Zhejiang Provincial People's Hospital, Hangzhou Medical College, Hangzhou 310014, Zhejiang, People's Republic of China. ${ }^{2}$ College of Letters \& Science, University of California, Berkeley, Berkeley, CA 94720, USA. ${ }^{3}$ Department of Critical Care Medicine, Ruijin Hospital, Shanghai Jiao Tong University School of Medicine, Shanghai 200025, People's Republic of China. ${ }^{4}$ Department of Emergency Medicine, Sir Run Run Shaw Hospital, Zhejiang University School of Medicine, Hangzhou 310016, Zhejiang, People's Republic of China. ${ }^{5}$ Department of Critical Care Medicine, Ruijin North Hospital, Shanghai Jiao Tong University School of Medicine, Shanghai 201800, People's Republic of China.

Received: 9 April 2020 Accepted: 4 June 2020

Published online: 18 June 2020

\section{References}

1. Naicker S, Yang CW, Hwang SJ, Liu BC, Chen JH, Jha V. The novel coronavirus 2019 epidemic and kidneys. Kidney Int. 2020. https://doi.org/10. 1016/j.kint.2020.03.001

2. Cheng Y, Luo R, Wang K, Zhang M, Wang Z, Dong L, et al. Kidney impairment is associated with in-hospital death of COVID-19 patients. medRxiv. 2020; doi: https://doi.org/10.1101/2020.02.18.20023242:2020.02.18. 20023242.

3. Wang D, Hu B, Hu C, Zhu F, Liu X, Zhang J, et al. Clinical characteristics of 138 hospitalized patients with 2019 novel coronavirus-infected pneumonia in Wuhan, China. JAMA. 2020. https://doi.org/10.1001/jama.2020.1585.

4. Chen N, Zhou M, Dong X, Qu J, Gong F, Han Y, et al. Epidemiological and clinical characteristics of 99 cases of 2019 novel coronavirus pneumonia in Wuhan, China: a descriptive study. Lancet. 2020;395(10223):507-13.

5. Yang X, Yu Y, Xu J, Shu H, Xia J, Liu H, et al. Clinical course and outcomes of critically ill patients with SARS-CoV-2 pneumonia in Wuhan, China: a singlecentered, retrospective, observational study. Lancet Respir Med. 2020. https://doi.org/10.1016/s2213-2600(20)30079-5.

6. Huang C, Wang Y, Li X, Ren L, Zhao J, Hu Y, et al. Clinical features of patients infected with 2019 novel coronavirus in Wuhan, China. Lancet. 2020;395(10223):497-506.

7. Liu Y, Yang Y, Zhang C, Huang F, Wang F, Yuan J, et al. Clinical and biochemical indexes from 2019-nCoV infected patients linked to viral loads and lung injury. Sci China Life Sci. 2020;63(3):364-74.

8. Arentz M, Yim E, Klaff L, Lokhandwala S, Riedo FX, Chong M, et al. Characteristics and outcomes of 21 critically ill patients with COVID-19 in Washington state. JAMA. 2020. https://doi.org/10.1001/jama.2020.4326.

9. Yang W, Cao Q, Qin L, Wang X, Cheng Z, Pan A, et al. Clinical characteristics and imaging manifestations of the 2019 novel coronavirus disease (COVID19):a multi-center study in Wenzhou city, Zhejiang, China. J Infect. 2020; 80(4):388-93. 
10. Zhou F, Yu T, Du R, Fan G, Liu Y, Liu Z, et al. Clinical course and risk factors for mortality of adult inpatients with COVID-19 in Wuhan, China: a retrospective cohort study. Lancet. 2020;395(10229):1054-62.

11. Wan S, Xiang Y, Fang W, Zheng Y, Li B, Hu Y, et al. Clinical features and treatment of COVID-19 patients in Northeast Chongqing. J Med Virol. 2020 https://doi.org/10.1002/jmv.25783.

12. Guan W, Ni Z, Hu Y, Liang W, Ou C, He J, et al. Clinical characteristics of coronavirus disease 2019 in China. N Engl J Med. 2020. https://doi.org/10. 1056/NEJMoa2002032

13. Shi S, Qin M, Shen B, Cai Y, Liu T, Yang F, et al. Association of cardiac injury with mortality in hospitalized patients with COVID-19 in Wuhan, China. JAMA Cardiol. 2020. https://doi.org/10.1001/jamacardio.2020.0950.

14. Wan X, Wang W, Liu J, Tong T. Estimating the sample mean and standard deviation from the sample size, median, range and/or interquartile range. BMC Med Res Methodol. 2014;14:135

15. Zhang Z, Wu P, Zhang J, Wang S, Zhang G. The effect of statins on microalbuminuria, proteinuria, progression of kidney function, and all-cause mortality in patients with non-end stage chronic kidney disease: a metaanalysis. Pharmacol Res. 2016;105:74-83.

16. Higgins JP, Thompson SG, Deeks JJ, Altman DG. Measuring inconsistency in meta-analyses. BMJ. 2003;327(7414):557-60.

17. Chen J, Qi T, Liu L, Ling Y, Qian Z, Li T, et al. Clinical progression of patients with COVID-19 in Shanghai, China. J Infect. 2020. https://doi.org/10.1016/j. jinf.2020.03.004.

18. Huang Y, Tu M, Wang S, Chen S, Zhou W, Chen D, et al. Clinical characteristics of laboratory confirmed positive cases of SARS-CoV-2 infection in Wuhan, China: a retrospective single center analysis. Travel Med Infect Dis. 2020. https://doi.org/10.1016/j.tmaid.2020.101606:101606.

19. Li Z, Wu M, Yao J, Guo J, Liao X, Song S, et al. Caution on kidney dysfunctions of COVID-19 patients. medRxiv. 2020; doi: https://doi.org/10. 1101/2020.02.08.20021212:2020.02.08.20021212.

20. Xu X-W, Wu X-X, Jiang X-G, Xu K-J, Ying L-J, Ma C-L, et al. Clinical findings in a group of patients infected with the 2019 novel coronavirus (SARS-Cov-2) outside of Wuhan, China: retrospective case series. BMJ. 2020;368:m606.

21. Qian GQ, Yang NB, Ding F, Ma AHY, Wang ZY, Shen YF, et al. Epidemiologic and clinical characteristics of 91 hospitalized patients with COVID-19 in Zhejiang, China: a retrospective, multi-Centre case series. Qjm. 2020. https:// doi.org/10.1093/qjmed/hcaa089.

22. Aggarwal S, Garcia-Telles N, Aggarwal G, Lavie C, Lippi G, Henry BM. Clinical features, laboratory characteristics, and outcomes of patients hospitalized with coronavirus disease 2019 (COVID-19): early report from the United States. Diagnosis (Berl). 2020;7(2):91-6.

23. Wang D, Yin Y, Hu C, Liu X, Zhang X, Zhou S, et al. Clinical course and outcome of 107 patients infected with the novel coronavirus, SARS-CoV-2, discharged from two hospitals in Wuhan, China. Crit Care. 2020;24(1):188.

24. Zhao XY, Xu XX, Yin HS, Hu QM, Xiong T, Tang YY, et al. Clinical characteristics of patients with 2019 coronavirus disease in a non-Wuhan area of Hubei Province, China: a retrospective study. BMC Infect Dis. 2020; 20(1):311.

25. Pei G, Zhang Z, Peng J, Liu L, Zhang C, Yu C, et al. Renal involvement and early prognosis in patients with COVID-19 pneumonia. J Am Soc Nephrol. 2020. https://doi.org/10.1681/asn.2020030276.

26. Hu L, Chen S, Fu Y, Gao Z, Long H, Wang JM, et al. Risk factors associated with clinical outcomes in 323 COVID-19 hospitalized patients in Wuhan, China. Clin Infect Dis. 2020. https://doi.org/10.1093/cid/ciaa539.

27. Wang L, Li X, Chen H, Yan S, Li D, Li Y, et al. Coronavirus disease 19 infection does not result in acute kidney injury: an analysis of 116 hospitalized patients from Wuhan, China. Am J Nephrol. 2020;51(5):343-8.

28. Goyal P, Choi JJ, Pinheiro LC, Schenck EJ, Chen R, Jabri A, et al. Clinical characteristics of Covid-19 in New York City. N Engl J Med. 2020. https://doi. org/10.1056/NEJMc2010419.

29. Li W, Moore MJ, Vasilieva N, Sui J, Wong SK, Berne MA, et al. Angiotensinconverting enzyme 2 is a functional receptor for the SARS coronavirus. Nature. 2003;426(6965):450-4

30. The team of Zhong Nanshan responded that the isolation of SARS-CoV-2 from urine remind us to pay more attention to the cleaning of individuals and families. Guangzhou Daily. https://baijiahao.baidu.com/s?id=1659222666 $751676890 \& w f r=$ spider $\&$ for $=p c$

31. Diao B, Wang C, Wang R, Feng Z, Tan Y, Wang H, et al. Human kidney is a target for novel severe acute respiratory syndrome coronavirus 2 (SARS-
CoV-2) infection. medRxiv. 2020; doi: https://doi.org/10.1101/2020.03.04. 20031120:2020.03.04.20031120.

32. Xu D ZH, Gong H, Chen J, Ye J, Meng T, et al. . Identification of a potential mechanism of acute kidney injury during the Covid-19 outbreak: a study based on single-cell transcriptome analysis. 2020; doi; https: //www. preprints. org/manuscript/202002.0331/v1

33. Su H, Yang M, Wan C, Yi LX, Tang F, Zhu HY, et al. Renal histopathological analysis of 26 postmortem findings of patients with COVID-19 in China. Kidney Int. 2020. https://doi.org/10.1016/j.kint.2020.04.003.

\section{Publisher's Note}

Springer Nature remains neutral with regard to jurisdictional claims in published maps and institutional affiliations.
Ready to submit your research? Choose BMC and benefit from:

- fast, convenient online submission

- thorough peer review by experienced researchers in your field

- rapid publication on acceptance

- support for research data, including large and complex data types

- gold Open Access which fosters wider collaboration and increased citations

- maximum visibility for your research: over $100 \mathrm{M}$ website views per year

At BMC, research is always in progress.

Learn more biomedcentral.com/submissions 